\title{
БЕЗОПАСНОСТЬ
}

\section{"КОМПЛЕКСНАЯ БЕЗОПАСНОСТЬ - 2021": от города безопасного к городу умному}

\section{С.Попов, Л.Набоких}

DOI: $10.22184 / 2070-8963.2021 .96 .4 .60 .65$

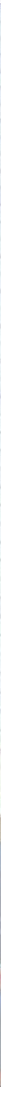

12 по 16 мая 2021 года основная площадка XIII Международного салона "Комплексная безопасность - 2021" впервые развернулась в армейском конгрессно-выставочном центре "Патриот" (Кубинка, Московская область). Одной из главных тем салона в этом году стал безопасный город.

Салон "Комплексная безопасность" проводится по распоряжению Правительства РФ с 2008 года. Организаторами мероприятия выступают совместно силовые ведомства страны - МЧС России и МВД России. За годы работы салон стал ключевым выставочно-конгрессным 
проектом федерального уровня, ориентированным на демонстрацию результатов реализации государственной политики и достижений в области обеспечения безопасности в различных сферах жизнедеятельности.

В событии на новой площадке приняли участие 252 предприятия и организации, под открытым небом было продемонстрировано более 350 единиц пожарной, спасательной, аварийновосстановительной и вспомогательной техники. Состоялись 130 мероприятий деловой и демонстрационной программы, которые посетило свыше 40 тыс. человек, а также более 350 иностранных представителей из 76 официальных делегаций.

Обеспечение комплексной безопасности немыслимо без надежных систем связи, поэтому неслучайно участие в ней операторов связи ("МегаФон", "Ростелеком", РСВО), производителей оборудования диспетчерской связи, профессиональной мобильной связи и др. Телекоммуникационная тематика поднималась на ряде конгрессных мероприятий в рамках салона: круглых столах "Система связи МЧС России в Арктической зоне Российской Федерации: проблемные вопросы, направления развития", "Перспективы развития системы связи пожарно-спасательного гарнизона", "Развитие и совершенствование Системы-112" и др.

Термин "Безопасный город" был одним из часто встречающихся в выставочных залах салона. В рамках салона прошла Международная научно-практическая конференция по перспективам построения и развития аппаратно-программного комплекса "Безопасный город", организованная департаментом образовательной и научно-технической деятельности МЧС России. Мероприятие прошло с участием представителей муниципальных структур из нескольких десятков регионов России, а открыл его первый заместитель главы МЧС Александр Чуприян, который подчеркнул, что эта конференция является одним из ключевых мероприятий деловой программы салона.

Интересно отметить, что из зала была установлена связь с автомобилем заместителя министра промышленности и торговли России Василия Шпака. Ведущий конференции спросил: сможет ли наша электронная промышленность обеспечить производство необходимых для АПК "Безопасный город" устройств? По расчетам, их потребуется более 1 трлн единиц. Заместитель министра уверенно ответил, что это по силам отечественному производству и, более того, такой заказ станет мощным драйвером развития отечественной электронной промышленности.

Генеральный конструктор АПК "Безопасный город" Оксана Якимюк начала свое выступление с диалога с представителем Владимирской области, который рассказал, что за пять лет работы системы в области предотвращено 240 критических ситуаций, это позволило спасти 20 тыс. жизней и не допустить потерь около 2 млрд руб. Однако, по мнению представителя региона, для полноценного внедрения систем безопасности не хватает политической воли. В настоящее время еще 15 тыс. объектов нуждаются в установлении датчиков, для этого необходимо 6 млрд руб., а таких средств у области нет.

В ходе дискуссии, которая развернулась после этого выступления, было отмечено, что в 10 субъектах РФ система действует, и очень важен настрой первых лиц региона на внедрение АПК "Безопасный город". О.Якимюк подчеркнула, что нужно нацеливаться в первую очередь не на фиксацию кризисных ситуаций, а на профилактику, предупреждение, прогнозирование. Именно они являются главными целями

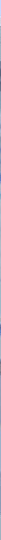

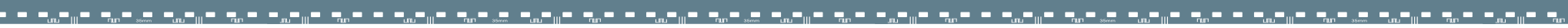


органов РСЧС и процессов обеспечения безопасности жизнедеятельности населения и городской инфраструктуры.

Важное место в экспозиции уделено представлению результатов работ по проектированию и созданию инфраструктуры АПК "Безопасный город" в различных субъектах РФ. На центральном экране можно познакомиться с работой региональной интеграционной платформы / ЕЦОР, запущенной в промышленную эксплуатацию в шести муниципалитетах Калининградской области. Платформа позволяет объединить в едином информационном пространстве четыре основных блока: транспортной безопасности, безопасности жизнедеятельности населения, экологической безопасности и межведомственного взаимодействия.

ЕЦОР собирает разнообразные данные с полевого уровня, интегрирует различные информационные системы муниципального и регионального уровней и осуществляет поддержку принятия решений при реагировании на различные происшествия. В единый центр поступает информация от систем мониторинга инженерных сооружений, ветхого и аварийного жилья, гидропостов, датчиков радиации, метеопостов, датчиков лесного пожара, систем видеонаблюдения и др.

Разработанный "ИскраУралТЕЛ" программный комплекс OC5000, внесенный в Единый реестр российского ПО, позволяет автоматизировать основные процессы ЕДДС и участников информационного взаимодействия в рамках АПК "Безопасный город", такие как действия

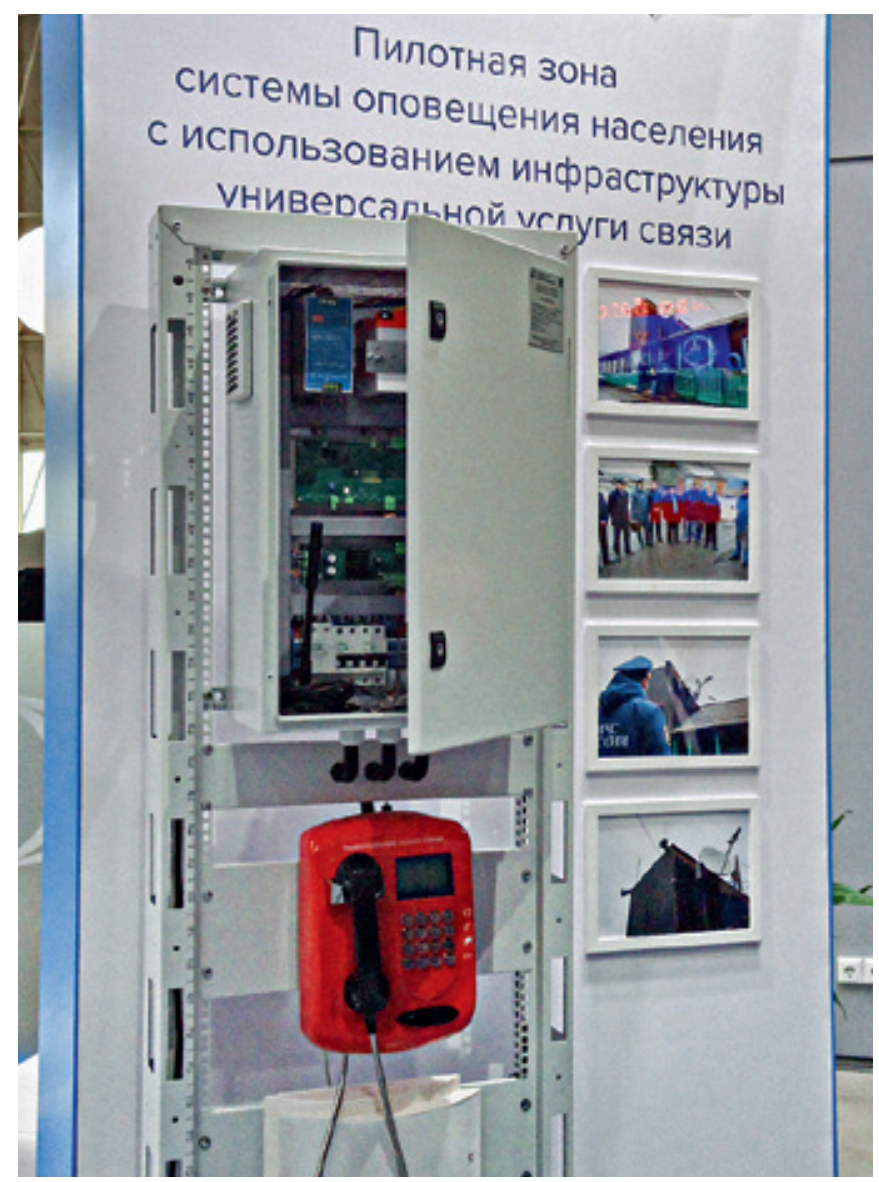

Таксофон УУс становится инфраструктурой системы оповещения

при получении информации о происшествиях и угрозах возникновения ЧС, подготовка донесений РСЧС, контроль персонального состава

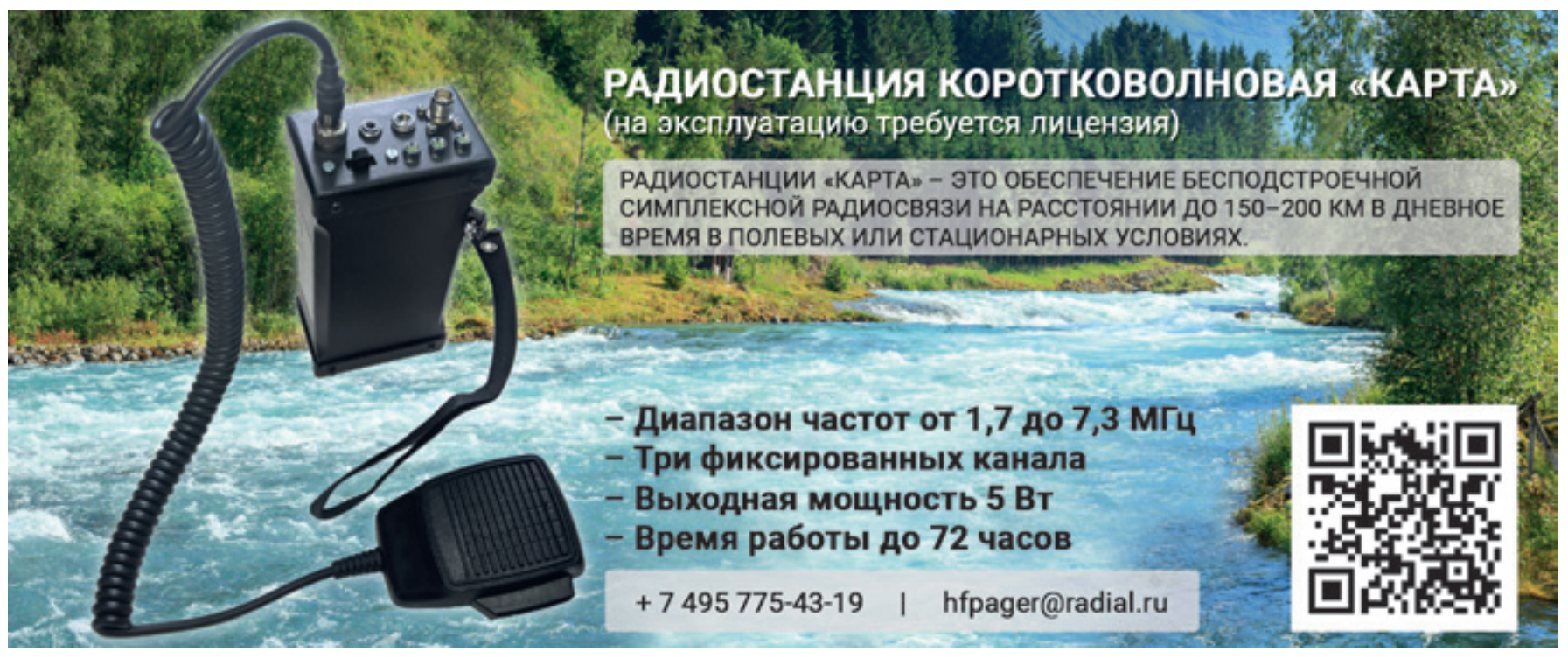


дежурных смен и подготовка строевых записок, подготовка сводок о происшествиях и ЧС и др. Важно подчеркнуть, что подсистема поддержки принятия решений позволяет моделировать и прогнозировать динамику распространения угроз при различных ЧС. Например, можно оценить динамику и размеры зон распространения лесных пожаров, зон затопления при паводке и пр. На сегодняшний момент в комплексе применяются более 10 модулей оценки развития ситуации для различных видов угроз.

Также на стенде продемонстрированы решения для реализации проектов в рамках стандарта "Умный город." В частности, мы представили рабочее место модуля мониторинга и контроля устранения аварий на объектах жилищно-коммунального хозяйства. Данное решение предназначено для обеспечения деятельности органов исполнительной власти субъекта РФ, органов местного самоуправления муниципальных образований, ресурсоснабжающих организаций, управляющих компаний в части фиксации оперативной и достоверной информации об авариях и инцидентах, планируемых и реализованных мероприятиях по их устранению на объектах ЖКХ, планирования отопительного сезона, а также передачи информации на федеральный уровень в автоматизированном режиме, в соответствии с поло жениями приказа Министерства строительства и жилищно-коммунального хозяйства России № 305/пр от 4 июня 2020 года "Об утверждении методических рекомендаций о порядке мониторинга и контроля устранения аварий и инцидентов на объектах ЖКХ".

Отдельная секция стенда "ИскраУралТЕЛ" посвящена решениям оперативно-технологической и диспетчерской связи для экстренных служб, спасательных формирований и других организаций. В ее рамках впервые на салонах "Комплексная безопасность" представлено наше решение по созданию частных сотовых сетей private LTE. Мы предлагаем ядро мобильной сети (ЕРС) четвертого поколения, полностью соответствующее требованиям стандартизации 3СРP. На его базе предприятия могут обеспечить беспроводной широкополосный доступ в локальном контуре, дополняющий корпоративную сеть связи. Мы также обеспечиваем интеграцию беспроводной сети в существующую сеть связи предприятия.

Как известно, ЕРС - один из наиболее затратных в финансовом плане элементов сети LTE. Наше решение существенно дешевле ядра сети

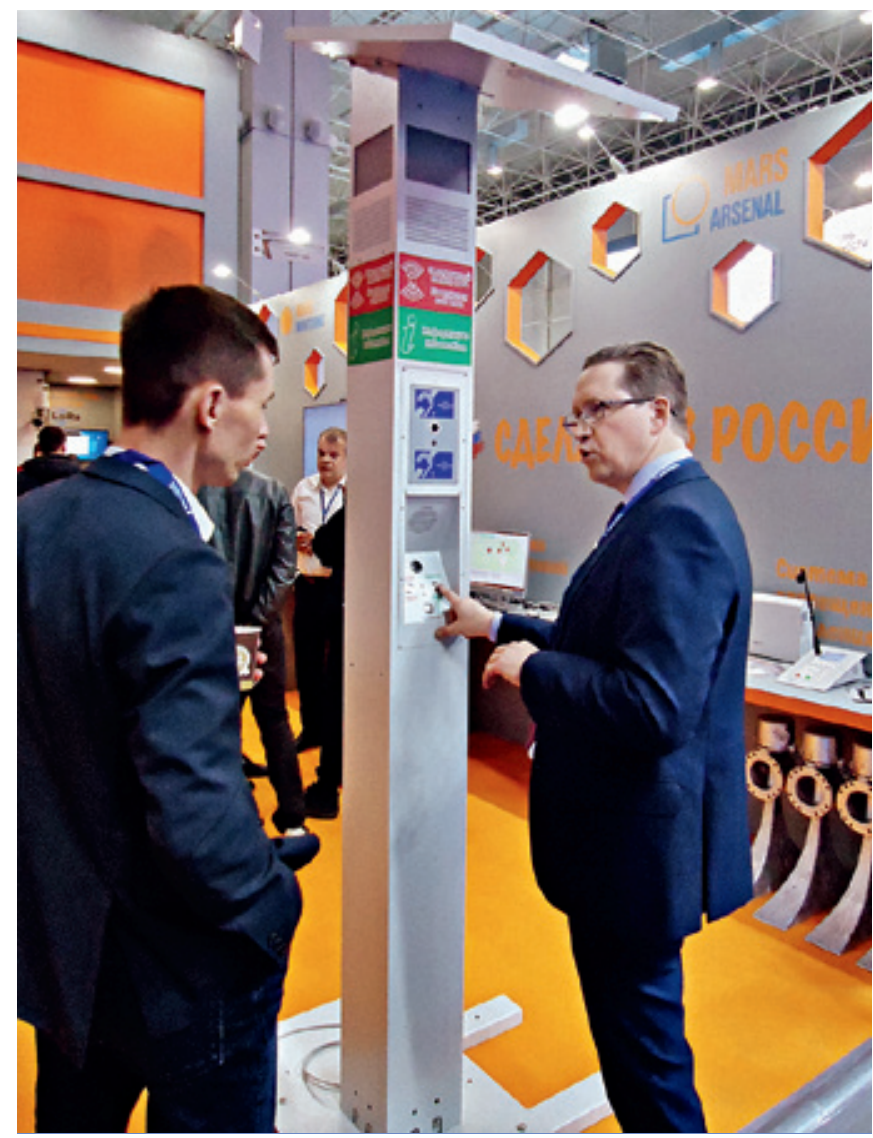

ГК "ТРИАЛИНК" впервые показала киоск выхода на Систему-112

LTE общего пользования. ЕРС от "ИскраУралТЕЛ" может работать как со специально выделенными для конкретного предприятия базовыми станциями (БС), так и через БС на основе выделения для private LTE отдельного сетевого слоя (slicing) сотовой сети общего пользования. Наша компания осуществила успешное тестирование данной технологии совместно с разными сотовыми операторами на площадках ряда российских предприятий горнодобывающей, металлургической, химической , автомобильной промышленности.

Большой двухэтажный стенд был у Группы компаний "ТРИАЛИНК". Компания, хорошо известная на рынке профессиональной мобильной радиосвязи, почти 15 лет назад занялась также разработкой средств оповещения населения. За эти годы было создано и внедрено несколько поколений программно-аппаратного комплекса оповещения населения КПАСО-Р "МАРС-АРСЕНАЛ", который сегодня хорошо известен во многих регионах России и не только. 
С работой этого комплекса можно было познакомиться на экспозиции под открытым небом.

На стенде "ТРИАЛИНК" в павильоне особый акцент был сделан на продвижении самого нового бренда компании - "Марс Мониторинг" (о дан ${ }^{-}$ ной платформе подробнее см. "ПЕРВАЯ МИЛЯ", 2021, № 1, с. 8-12). О дальнейшем развитии "Марс Мониторинг" рассказал основатель и руководитель Группы компаний "ТРИАЛИНК" А.Н.Шмурьев.

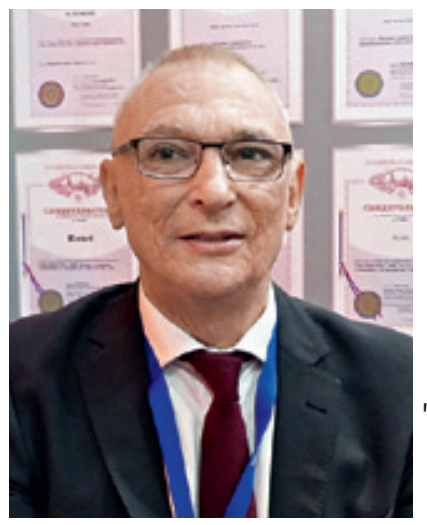

Алексей ШМУРЬЕВ

генеральный директор ООО "ТРИАЛИНК Груп"

Про фе с сион а лы сферы обеспечения безопасности хорошо знают бренд нашей комПании "МАРС-АРСЕНАЛ". "Марс Мониторинг" стал логическим продолжением комплекса "МАРСАРСЕНАЛ", в качестве дополнения к которому более 10 лет назад была создана станция контроля уровня воды (СКУВ) в реках и водоемах. Она стала первым нашим решением мониторинга.

Система оповещения является одним из важных элементов безопасного города, но сегодня пришло время создания не просто безопасных, но умных городов и поселений. А город можно считать умным, если его системы действуют на основе метаданных, которые могут быть получены только на основе разветвленной и современной системы мониторинга множества параметров. Возможно, уже скоро пока существующие по отдельности понятия безопасного города и умного города сольются в единое и неразрывное: современный город.

"Марс Мониторинг" непрерывно развивается. В этом году с помощью партнера из г. Томск мы дополнили наш комплекс возможностью предоставления 3D-моделей. Такое решение позволяет создать цифровой образ объекта мониторинга, в том числе многоэтажного, что значительно упрощает принятие решений по управлению этим объектом.

Надо отметить, что в нашей станции контроля уровня воды впервые в России осуществлено совмещение замера уровня водной поверхности с фотографированием водной глади в момент замера. Это весьма важно, так как в реальных условиях в рассматриваемый момент может проплывать бревно, лодка и т.п. На основании накопленного нашей компанией большого объема данных с установленных СКУВ существенно улучшен алгоритм оценки уровня воды, что практически исключает ложные срабатывания системы.

В текущем году в нашей системе мониторинга впервые появилось оборудование отечественного стандарта LoRaWAN Ru. Во многих случаях беспроводное решение на базе этого стандарта получается экономичнее, чем подключение датчиков проводами. Оборудование данного стандарта обеспечивает уверенную связь на расстоянии нескольких километров.

На стенде можно познакомиться с базовыми станциями LoRaWAN нашего производства. Они изготавливаются на базе микросхем Semtech Electronics, а ПО для них полностью создано программистами "ТРИАЛИНКа". Добавлю, что в ряде региональных проектов "Марс Мониторинг" используется и другое беспроводное оборудование "ТРИАЛИНКа" - стандарта DMR. Это, в частности, Брянская область и Чеченская республика.

Масштабным внедрением "Марс Мониторинг" стал осуществляемый "ТРИАЛИНКом" совместно с госкорпорацией "Ростех" пилотный проект "Безопасный город" в Мурманской области. В его рамках почти 40 объектов ЖКХ оснащены разветвленными сетями мониторинга. Например, на узлах теплоснабжения система контролирует объем и температуру теплоносителя, передаваемого в город и возвращающегося на объект. Контролируются также напряжение в электросети, температура воздуха в окружающей среде, работа автоматики и другие параметры. "Марс Мониторинг" интерпретирует получаемые с датчиков данные в простой визуальной форме, а также передает их в аналитическое программное обеспечение верхнего уровня.

На стенде можно познакомиться и с еще одной новой разработкой нашей компании для сферы безопасности - вандалозащищенным киоском (колонной) выхода на Систему-112. Это решение, помимо обеспечения экстренного вызова, может выполнять целый ряд задач. Заказчику достаточно поставить "галочки" в спецификации и киоск дооснащается точкой доступа Wi-Fi, солнечной батареей и дополнительным аккумулятором.

Нашей новой разработкой заинтересовались уже и в Казахстане. Там вскоре будет организовано изготовление таких киосков. 